\title{
Cosmética y experimentación en animales
}

Keywords: derecho; legislación; jurisprudencia; animal

En fecha reciente (11.3.2013) [1] se ha hecho plenamente vigente y exigible la prohibición del uso de animales para la experimentación en productos cosméticos, y, por ende, la venta de los mismos.

No se trata de una novedad absoluta, pues tal prohibición no es más que la implementación de uno de los extremos contenidos en el recién publicado Real Decreto 53/2013, de 1 de febrero[2] por el que se aplica en España la directiva europea de 11 de marzo de 2003, emanada hace ya 10 años [3].

Se trata de uno de los aspectos que, probablemente más consenso concitarán entre el público en general, en relación a la experimentación en animales en beneficio de los humanos. Produce rechazo que para comprobar la eficacia de un fregasuelos, de un champú, de un detergente o de una crema hidratante, tenga que someterse a pruebas de toxicidad a animales de laboratorio. Si tal rechazo no es más evidente y está más extendido se debe a que se desconoce la realidad de la experimentación, su necesidad, su regulación cada vez más estricta y la formación de una verdadera conciencia ciudadana, informada y objetiva.

Ha habido, en este sentido, compañías pioneras en la supresión de los tests en animales tanto en productos cosméticos ("The Body Shop", p.e.), como en productos de aseo, cosmética y limpieza (las marcas "Bosque Verde" y "Deliplus", de "Mercadona", p.e.). Cada vez son más los usuarios que, antes de comprar, miran la etiqueta del producto, para asegurarse de que no ha habido experimentación en animales. Por ello, cada vez son más las marcas que suprimen los tests de prueba en animales. Un ejemplo reciente e impactante, por la calidad y el reconocimiento mundial de la firma, se debe a la compañía japonesa Shiseido, que desde 2009 estaba en el punto de mira de las protestas de organizaciones internacionales, por el uso de animales en sus protocolos de experimentación. Finalmente, sus productos no serán testados en animales, a partir de abril del 2013 [4].

Lo que suscita la experimentación animal de rechazo popular es inversamente proporcional a su desconocimiento y al de las medidas que, lenta pero rigurosamente, viene aplicando el Derecho.

En los recientes textos legislativos, se prioriza el bienestar del animal y la aplicación de técnicas que supongan un avance en la sustitución de los experimentos en animales por técnicas alternativas, cada vez más desarrolladas, por ser más severamente exigidas por los comités éticos que la nueva legislación exige en cada centro donde se experimente con animales. No obstante, queda un largo camino por recorrer para el que, por fortuna, ya se ha dado el primer paso.

Desde DA webCenter queremos contribuir a que se conozca la cobertura que el Derecho ofrece los animales en la experimentación y a fomentar el diálogo, tan necesario, entre científicos y juristas. Por tal razón, venimos publicando todo este mes, artículos relativos al tema[5] e incluimos también un comentario a la sentencia del TSJ de Cataluña[6], referida al centro de Camarles, que está en el foco de atención de la noticia y pone de relieve la necesidad de una revisión de las instalaciones, para hacer plenamente vigente las últimas disposiciones legales. 
Animal Law Profesor Universitat Autònoma de Barcelona

[1] La Directiva 2003/15/CE introdujo disposiciones relativas a los ensayos con animales en la Directiva 76/768/CEE sobre cosméticos. En consecuencia, la experimentación con animales en la Unión ya está prohibida desde 2004 para los productos cosméticos y desde 2009 para los ingredientes cosméticos («prohibición de experimentación»). Desde marzo de 2009, también está prohibida la comercialización en la Unión de productos cosméticos que contengan ingredientes experimentados en animales («prohibición de comercialización»). En lo que se refiere a las consecuencias más complejas para la salud humana (toxicidad por administración repetida, incluidas la sensibilización cutánea y la carcinogenicidad, así como la toxicidad para la función reproductora y toxicocinética) la fecha de la prohibición de comercialización se amplió al 11 de marzo de 2013.

[2] Real Decreto 53/2013 de 1 de febrero, por el que se establecen las normas básicas aplicables para la protección de los animales utilizados en experimentación y otros fines científicos, incluyendo la docencia;

[3] Vid. documento interno

[4] Vid. Oipa

[5] Vid. Patri VERGARA, Nueva legislación sobre la protección de los animales utilizados en investigación; Maria GONZÁLEZ

LACABEX, La ciencia, también de su lado; Martí PUMAROLA, Animales e investigación en neuropatología veterinaria

[6] Vid. Anna MULÀ, Experimentación con animales: Sentencia del Tribunal Superior de Justicia de Cataluña n 315, de 31/3/2006 